\title{
The feasibility of producing patient-specific acrylic cranioplasty implants with a low-cost 3D printer
}

\author{
Eddie T. W. Tan, MRCSEd, Ji Min Ling, MRCSEd, and Shree Kumar Dinesh, FRCS \\ Department of Neurosurgery, National Neuroscience Institute, Singapore
}

\begin{abstract}
OBJECTIVE Commercially available, preformed patient-specific cranioplasty implants are anatomically accurate but costly. Acrylic bone cement is a commonly used alternative. However, the manual shaping of the bone cement is difficult and may not lead to a satisfactory implant in some cases. The object of this study was to determine the feasibility of fabricating molds using a commercial low-cost 3D printer for the purpose of producing patient-specific acrylic cranioplasty implants.
\end{abstract}

METHODS Using data from a high-resolution brain CT scan of a patient with a calvarial defect posthemicraniectomy, a skull phantom and a mold were generated with computer software and fabricated with the 3D printer using the fused deposition modeling method. The mold was used as a template to shape the acrylic implant, which was formed via a polymerization reaction. The resulting implant was fitted to the skull phantom and the cranial index of symmetry was determined.

RESULTS The skull phantom and mold were successfully fabricated with the 3D printer. The application of acrylic bone cement to the mold was simple and straightforward. The resulting implant did not require further adjustment or drilling prior to being fitted to the skull phantom. The cranial index of symmetry was $96.2 \%$ (the cranial index of symmetry is $100 \%$ for a perfectly symmetrical skull).

CONCLUSIONS This study showed that it is feasible to produce patient-specific acrylic cranioplasty implants with a low-cost 3D printer. Further studies are required to determine applicability in the clinical setting. This promising technique has the potential to bring personalized medicine to more patients around the world.

http://thejns.org/doi/abs/10.3171/2015.5.JNS15119

KEY WORDS 3D printing; acrylic bone cement; additive manufacturing; cranioplasty; mold

$\mathrm{T}$ HE reconstruction of a skull vault defect, termed cranioplasty, has a rich and fascinating history. For at least 5 millennia, surgeons have patched cranial defects with an immensely diverse range of materials ranging from fruit shells to sheep scapulae and man-made plastics. ${ }^{42}$ Even today, the pursuit of the perfect cranioplasty material and technique continues.

Skull defects are often the direct result of surgical decompressive craniectomy performed for acute neurosurgical emergencies. ${ }^{23}$ The use of a patient's original bone flap for cranioplasty is theoretically sound and avoids the problems related to the use of bone from other sources, such as human cadavers (allografts) or animals (xenografts), or the use of synthetic materials. In practice, however, cranioplasty using these bone flaps, which have been stored for a period of time either in a surgically created subcutaneous pocket or in a medical freezer, is plagued with a not insignificant risk of infections and bony resorption. ${ }^{8,11,22}$ With unnatural storage, the nature and content of these bone flaps are changed permanently, hindering successful reincorporation as part of the skull vault. Loss of osteogenesis probably plays a role; studies on human calvarial bone flaps have shown a diminution of osteoblasts after both subcutaneous ${ }^{44}$ and low-temperature ${ }^{7}$ storage. Using 
autografts from other parts of the body, such as the contralateral skull vault or the ribs, is feasible but incurs the cost of additional donor site morbidity. ${ }^{37,51}$

Many synthetic materials have been used successfully in cranioplasty. ${ }^{20,42,43}$ Today, commonly used synthetic materials include acrylic, hydroxyapatite, titanium, ceramics, and polyetheretherketone (PEEK) ${ }^{43}$ Although all of these materials may be used to produce prefabricated patientspecific implants, acrylic and hydroxyapatite are available in cement form that can be shaped intraoperatively. Commercially available prefabricated implants are designed to approximate the patient's calvarial shape but can be costly. The use of acrylic bone cement, also known as polymethylmethacrylate, is appealing due to a number of desirable properties, which include biocompatibility, malleability, strength, and a long history of use as an implant. ${ }^{42}$ It is also widely available due to its role in many orthopedic operations. ${ }^{35}$ The mixing of the liquid and powder components of acrylic bone cement initiates an exothermic polymerization reaction, culminating in a soft and malleable putty which hardens in less than 20 minutes from the time of mixing. Similar to a craftsman, the surgeon must manually sculpt the putty into the approximate size, shape, and fit of the missing bone flap within the time window imposed by the polymerization process. This requires considerable skill and is a major obstacle to the optimal application of acrylic bone cement in cranioplasty. Despite the development of special techniques to aid manual shaping, ${ }^{29,46,53}$ the ability to consistently achieve a satisfactory result remains a challenge. This is particularly so when dealing with large defects.

By using molds that are cast based on the original bone flaps, $, 310,57$ the surgeon is able to easily create an implant in the likeness of the original bone flap. Obviously, this is not possible in cases where the bone flap has been discarded, destroyed, or is simply missing. Three-dimensional printing technology, also known as additive manufacturing, allows the rapid production of customized objects ${ }^{6}$ and has immense potential in the medical field, particularly for surgical planning and implant production. ${ }^{40}$ With computer 3D modeling software and the patient's neuroimaging data, a mold can be designed, fabricated with this technology, and used to shape acrylic bone cement into an implant with good results. ${ }^{27,36}$ Although promising, this method has not been widely adopted, at least in part due to limited access to expensive commercial and industrial 3D printers. The proliferation of low-cost desktop 3D printers has the potential to change this. We conducted a preclinical study on the feasibility of producing patient-specific cranioplasty implants with a low-cost desktop 3D printer and acrylic bone cement.

\section{Methods}

High-resolution CT data from a patient who previously underwent a unilateral frontotemporoparietal decompressive craniectomy was obtained via a volumetric spiral CT scan of the head performed with a 320-slice commercial CT scanner (Aquilion ONE 320; Toshiba America Medical Systems, Inc.). The data, in DICOM format, was transferred to a computer workstation for manipulation.
With computer software (3D Slicer 4.3.1; Surgical Planning Laboratory), image segmentation was performed using the threshold method, taking advantage of the large difference in CT density between the bony skull and the soft tissue (Fig. 1A and B). Segmentation enabled the generation of 3D models of a skull (Fig. 1C) and a mold (Fig. $1 \mathrm{E})$. For the skull model, a digital 3D model of the entire skull was generated based on the segmentation and exported in the stereolithography file format.

For the mold, a more complicated process was required. First, 2 digital 3D models were generated. The first model (the "normal" model) was generated based on the segmentation as performed above. The second model (the "dilated" model) was generated after dilating the segmentation by $1 \mathrm{~mm}$. When the acrylic implant is subsequently produced, this dilation translates into a 1-mm gap between the implant and the patient's skull defect, avoiding an excessively tight fit. These 2 models were then exported in the stereolithography file format.

Next, using 3D modeling software (MeshMixer 2.4; Autodesk, Inc.), a mirror image of the normal model was created, resized, and overlapped onto the dilated model. The skull defect on the dilated model was then matched to the corresponding intact skull on the mirror image model; thus, when the acrylic implant is subsequently formed, it derives its contour from the patient's own intact contralateral skull. The mold design deliberately excluded parts of the squamous temporal bone, which, in a patient undergoing cranioplasty, would be covered by the temporalis muscle and not contribute to the shape of the head. Finally, portions of the skull not immediately adjacent to the craniectomy defect were removed to reduce the overall size of the mold.

The 3D models of both the skull and the mold were "sliced" with computer software (MakerWare 2.4.1.35; MakerBot Industries) with the following settings: infill, $20 \%$; shells, 2; layer height, $0.1 \mathrm{~mm}$; extrusion temperature, $230^{\circ} \mathrm{C}$; speed while extruding, $90 \mathrm{~mm} /$ second; speed while traveling, $150 \mathrm{~mm} / \mathrm{second}$; and the addition of both raft and supports. The aptly named slicing process digitally cuts a 3D model into a contiguous series of thin slices, and then converts these slices into movement instructions for the extruder of the 3D printer. These instructions were exported to a file in $\mathrm{x} 3 \mathrm{~g}$ format and sent to the desktop 3D printer (MakerBot Replicator 2; MakerBot Industries), which fabricated the skull (Fig. 1D) and the mold (Fig. 1F) models in polylactic acid using the fused deposition modeling method.

This 3D printing technique ${ }^{24}$ works by first heating a thermoplastic beyond its melting point, thereby liquefying it. The liquefied material is then pushed through an extruder mounted on a movable gantry. The extruder moves according to the instructions generated by the slicing process. The extruded material rapidly cools, bonding to either the build platform (for the first layer) or the previous layer (for subsequent layers). By laying down layer after layer in a precise manner based on the shape and dimensions of the digital 3D model, the digital model is thus converted into a physical object.

The powder and liquid components of acrylic bone cement (Surgical Simplex P Radioopaque bone cement; 

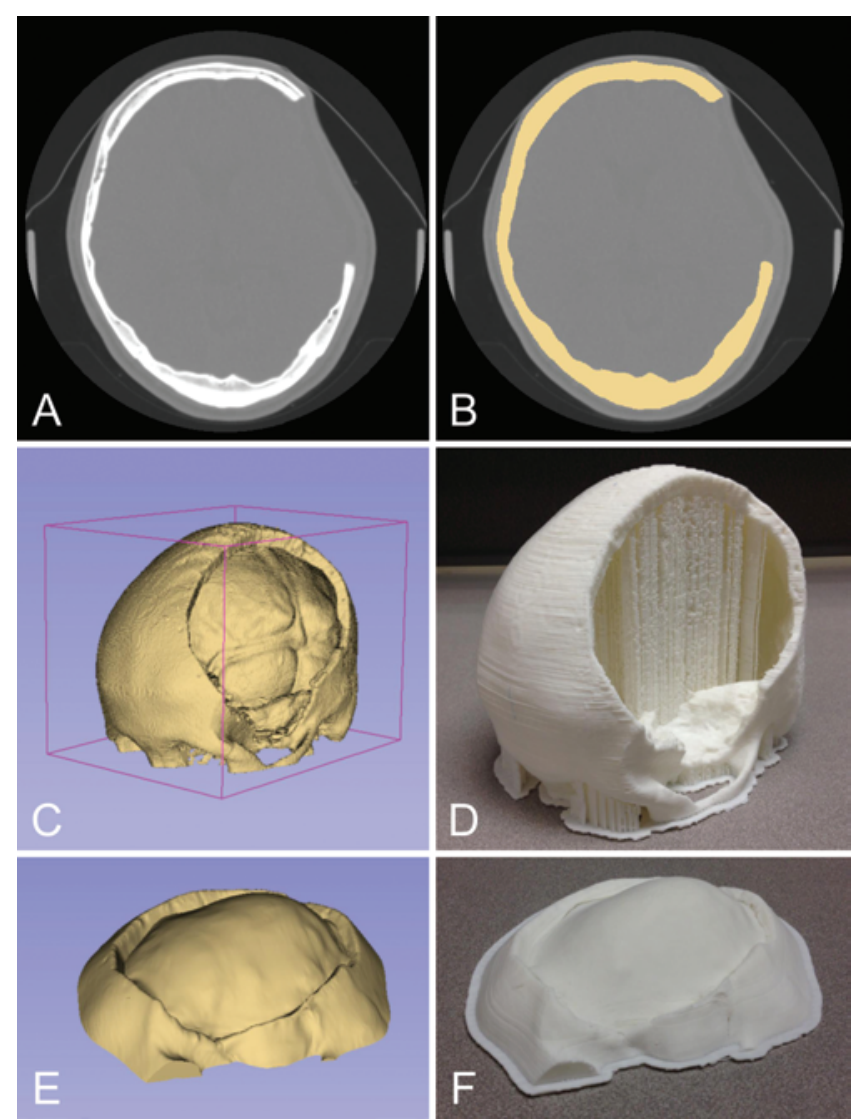

FIG. 1. Images demonstrating the threshold method of segmentation, showing the before $(A)$ and after $(B)$ results. The fused deposition modeling method accurately transforms computer-generated 3D models (skull [C] and mold [E]) into physical models (skull [D] and mold [F]). The support structures in the $3 \mathrm{D}$ printed skull phantom (D) allow the fabrication of the overhanging portions. A, B, C, and $\mathrm{E}$ are computer screen captures; $D$ and $F$ are photographs.

Stryker Corporation) were mixed in a plastic bowl to initiate the polymerization reaction. The mixture was stirred with a plastic spatula until it no longer adhered to the surgeon's glove. At that point, it was ready to be shaped. The bone cement putty was first stretched out like a disk to a uniform thickness and applied to the 3D printed mold, ensuring that the edges of the bone cement abutted the corresponding edges on the mold (Fig. 2A). The bone cement was allowed to harden and then was removed from the mold. With this method, the mold design and bone cement application process act in synergy to ensure that the outer contour of the newly formed acrylic cranioplasty implant approximates the contour of the missing bone flap. This is achieved in the following way. The middle portion of the mold that shapes the bone cement is based on the contour of the intact contralateral skull. By applying bone cement of uniform thickness to the mold, the contour of the mold is translated into the contour of the external surface of the formed implant. In its clinical application, the implant is anchored to the skull by plating its external surface to the skull surface, thus negating the effect of any difference in thickness between the implant and the patient's skull.
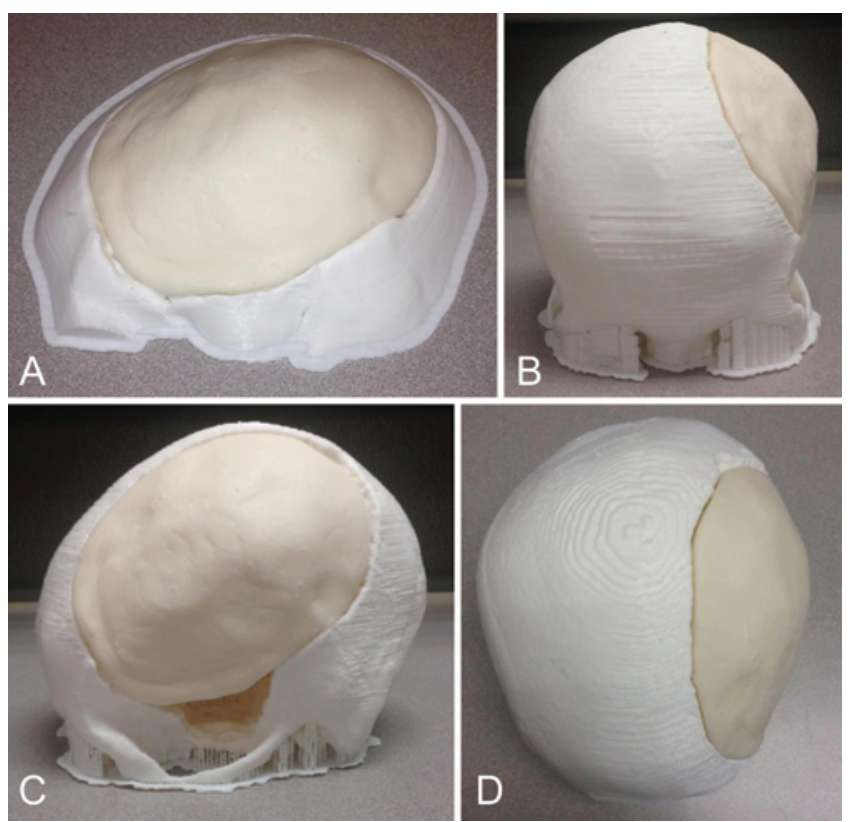

FIG. 2. Photographs showing application of bone cement to the mold for generation of the implant (A). The implant had a good fit to the skull phantom and approximated the contour of the contralateral skull, as demonstrated by views from the front (B), side (C), and top (D). Note that on the side view, the implant does not extend into the inferior temporal portion of the skull.

The 3D printed skull was used as a phantom onto which the newly generated acrylic implant was fitted (Fig. 2BD). A digital photograph was taken of the skull phantom fitted with the implant to determine the cranial index of symmetry $^{58}$ using image analysis software (ImageJ $1.48 \mathrm{v}$; National Institutes of Health). To determine the cranial index of symmetry, we first measured the total area of the skull. Next, the midline was identified and the skull divided into 2 halves. One half was reversed right to left and overlapped onto the other half. The area of overlap between the 2 halves was calculated and doubled (to account for the 2 halves of the skull). The cranial index of symmetry is the proportion (expressed as a percentage) of the overlapping skull area to the total skull area. For a perfectly symmetrical skull with complete overlap between its 2 halves, the cranial index of symmetry is $100 \%$. Although originally conceived as an assessment for the severity of plagiocephaly in children, ${ }^{58}$ this simple but intuitive method has been applied to evaluate the symmetry of cranial reconstructions in adult patients with skull defects. ${ }^{28}$

\section{Results}

Both the skull phantom and the mold were designed and fabricated successfully. The generation and design of the digital models were completed in 60 minutes. The 3D models of the skull and the mold were fabricated in approximately 6 hours and 40 minutes and 33 hours and 20 minutes, respectively. The layer height setting was 0.1 $\mathrm{mm}$. Printing with thicker layer heights, such as 0.2 or 0.3 
$\mathrm{mm}$, is possible and results in a shorter printing time but a coarser model.

To form the acrylic cranioplasty implant, 2 units of the bone cement were used; the first attempt using 1 unit resulted in a thin and uneven implant. Application of the bone cement in its putty form to the 3D printed mold was simple and straightforward. Fitting the implant to the 3D printed skull phantom did not require any further drilling or modification. The calculated cranial index of symmetry was $96.2 \%$.

\section{Discussion}

Personalized medicine is poised to revolutionize the modern practice of medicine. In the treatment of cancer, the recognition of the differences in carcinogenesis among individuals has led, in some instances, to targeted molecular therapies with remarkable efficacy. ${ }^{4}$ Similarly, the refinement of imaging technology, coupled with the capability to produce patient-specific implants, has given rise to a proliferation of alternatives to traditional off-the-shelf implants. Progress in cranioplasty has not lagged. In the past 20 years or so, much has been achieved through research on the techniques to produce customized cranioplasty implants. ${ }^{13,14,19,21,27,34,36,48,49,54,56}$ Nevertheless, these impressive techniques have generally remained in the respective laboratories and universities in which they were developed. This is because they require technical expertise as well as expensive, sophisticated software and machinery that are beyond the means of most surgeons and hospitals. As a result, the majority of patients requiring cranioplasty have not benefitted from the advances in the field. There are commercial companies that provide these services outside of academia; the problem is that they typically do so for a hefty fee.

In this study, we show that it is feasible to produce a patient-specific cranioplasty implant by using a low-cost desktop 3D printer coupled with cheap and widely available acrylic bone cement. All of the software that we used is free and downloadable via the internet. The authors, despite being surgeons with no specialized training in either computer 3D modeling or engineering, were able to design and fabricate the mold, and then use the mold to produce a customized cranioplasty implant. The implant had a good fit to the skull phantom and resulted in a cranial index of symmetry of $96.2 \%$. To put this into perspective, in the original study on plagiocephaly, the mean cranial index of symmetry of normal children was $96.3 \%$, whereas that of children with plagiocephaly was $81.9 \% .{ }^{58}$ In a study with adult patients, which calculated the cranial index of symmetry of skull defects that were reconstructed digitally, researchers reported an astounding mean score of $99.2 \%$; however, this result must be viewed in light of the fact that they examined only digital models, which tend to be closer to perfect and more idealized.

The process of mold and implant fabrication should be as simple as possible while being applicable in a wide variety of cases. Mold fabrication techniques that require an intact bone flap ${ }^{3,10,57}$ cannot be used when the original bone flap is not available. The method of mold production by direct casting of the defect on the patient's head $2,25,50$ is inaccurate due to the presence of soft tissue and the absence of the normal calvarial curvature. These factors explain our choice to design the mold based on the patient's intact contralateral skull by the use of computer 3D modeling techniques based on high-resolution CT scan data. Most published techniques for producing molds using computer $3 \mathrm{D}$ modeling and $3 \mathrm{D}$ printing ${ }^{12,17,31}$ require fabrication via $3 \mathrm{D}$ printing of both the skull defect and a preliminary implant. This is followed by alteration of the implant by hand to fit the defect and then casting of the implant to create a mold.

We have condensed these steps by directly designing the mold digitally for fabrication using 3D printing. Our technique is similar to that used by Kim and colleagues, ${ }^{27}$ albeit with one difference. To create their implant, Kim et al. compressed bone cement between the 2 parts of their mold, whereas we applied bone cement to the surface of our 1-part mold. We feel that our mold design is simpler and yet able to create a sufficiently accurate implant. Final$\mathrm{ly}$, in contrast to mold techniques that produce the acrylic implant preoperatively, $2,12,25,31,50$ we prefer to sterilize the mold for the intraoperative fabrication of the acrylic cranioplasty implant. Intraoperative implant fabrication not only deviates less from the recommended usage of the bone cement but also allows for the immediate reproduction of another implant should the need arise.

To translate our results to the clinical setting and produce implants for use in patients, more research is needed. Here, 2 considerations are paramount: the accuracy of the 3D printing process and the material used to fabricate the mold. To our knowledge, there are no published peer-reviewed studies on the accuracy of the particular 3D printer used in this study. Our own tests, in which geometrical objects (e.g., cubes) of known dimensions are 3D printed, consistently show that measured dimensions of the 3D printed objects do not deviate from the original digital dimensions by more than $0.5 \mathrm{~mm}$ (unpublished data). From the literature, a generalization may be inferred by analyzing published studies that examined the accuracy of 3D printers using the same method of 3D printing, i.e., the fused deposition modeling method. In one such study, ${ }^{15}$ researchers measured bone thickness at different sites as well as distances between anatomical landmarks on 3D printed skulls and mandibles. Comparisons were made between the measurements on the 3D printed models and those on their corresponding digital models. For skulls, they found a mean difference (error) of just $0.1 \mathrm{~mm}$. In another study, ${ }^{45}$ researchers imaged cadaver shoulder and hip joints with CT scans. With the resulting imaging data, 3D models were computer generated and then fabricated using fused deposition modeling. Next, by laser scanning of both the original cadaveric joints and the 3D printed models, they generated pairs of digital 3D models for comparison. Here, they also found a low overall error of $0.3 \mathrm{~mm}$. Although these 2 studies used different methodologies and studied different parts of the human body, they arrived at remarkably similar results $(0.1 \mathrm{~mm}$ in one study and 0.3 $\mathrm{mm}$ in the other). Taken together, this submillimeter accuracy attests to the high degree of precision achievable by the fused deposition modeling method of 3D printing.

In our study, we used polylactic acid to fabricate both the skull phantom and the mold. Polylactic acid is a biodegrad- 
able and biocompatible thermoplastic with widespread applications in both medical and nonmedical fields. ${ }^{26,30}$ It has been used for implantation in the human body for functions ranging from soft tissue fillers ${ }^{5,52}$ to fracture fixing screws. ${ }^{1}$ With a glass transition temperature of $55^{\circ} \mathrm{C}$, ${ }^{16}$ it is unsuitable for the autoclave. Hydrogen peroxide plasma and ethylene oxide both sterilize at compatible temperatures and have been used to sterilize objects constructed with polylactic acid without causing any significant changes to their biomechanical properties. ${ }^{39}$ With material biocompatibility as well as sterilization addressed, one unresolved issue remains, which is the potential effect that the temperature elevation during bone cement polymerization may have on a polylactic acid mold. In one laboratory experiment, ${ }^{18}$ the surface temperature of the bone cement reached an average of $63.5^{\circ} \mathrm{C}$ during polymerization. Whether this could adversely affect the mold remains uncertain. While conducting our study, we did not detect any appreciable physical changes in the mold after application of the bone cement. Nonetheless, further study is required on the effects that the bone cement polymerization process may have on $3 \mathrm{D}$ printing materials.

The 3D printer used in this study costs approximately US \$2000, which is far less than the costs of commercial and industrial 3D printers. The economic consideration of any health care intervention is important. Today, health care is consuming an ever-increasing share of the total output generated by human endeavors; in 2011 alone, the world spent a staggering US $\$ 6.9$ trillion on health care. ${ }^{55}$ The enormous health care expenditure has been ascribed to, among other reasons, the high and rising costs of technological advancements in the diagnosis and treatment of diseases. ${ }^{9}$

One such advancement is the advent of prefabricated patient-specific implants in the field of cranioplasty. Prefabricated implants, such as those made of hydroxyapatite, PEEK, and titanium, are commercially available and have been used with good results. . $^{33,38,41,47}$ As we alluded to, commercial products are expensive, having been developed and marketed with the primary intention of generating profits. This is supported by the published literature. In an American study, ${ }^{38}$ the average cost of PEEK implants was approximately US $\$ 10,450$, while in a Dutch study ${ }^{33}$ on 10 titanium implants and 7 PEEK implants, the average cost was US \$11,200 (€10,000; $€ 1=$ US \$1.12). The average cost of hydroxyapatite implants was US $\$ 7840(€ 7000)$ in an Italian study ${ }^{47}$ and US $\$ 8960(€ 8000)$ in a French study. ${ }^{32}$

In contrast, an acrylic implant made using our technique costs, in terms of manpower (a neurosurgical resident's wages for 1 day $=$ SG [Singapore] \$400) and consumables (cost of 3D printing material $=$ SG $\$ 10$; cost of 2 units of bone cement $=$ SG $\$ 150$; cost of 1 cycle of hydrogen peroxide plasma sterilization = SG \$30), approximately US \$430 (SG \$590; SG \$1 = US \$0.73), an order of magnitude less than the cost of commercial prefabricated implants.

That these commercial implants can contribute as much as $64 \%$ to the total cost of cranioplasty (including the costs of the implant, anesthesiology, surgery, and the entire hospital stay), according to one study, ${ }^{33}$ is astounding. The high cost renders them plainly unaffordable to many patients. Our local experience is no different; despite living in a relatively affluent country, Singaporean patients not uncommonly decide against the PEEK implant due to financial constraints and opt instead for the cheaper option of surgeon-shaped acrylic implant. Thus, it is imperative that we develop alternatives that benefit not only the rich and the fortunate.

\section{Conclusions}

In this study, we showed that it is feasible to produce patient-specific acrylic cranioplasty implants with a lowcost desktop 3D printer. Further studies are planned to bring this technique from the proverbial bench to the patient's bedside. One can only hope that our work, together with that of others, may finally allow personalized medicine to reach its full potential and bring about the next revolution in health care.

\section{References}

1. Agarwal S, Gupta A, Grevious M, Reid RR: Use of resorbable implants for mandibular fixation: a systematic review. J Craniofac Surg 20:331-339, 2009

2. Akan M, Karaca M, Eker G, Karanfil H, Aköz T: Is polymethylmethacrylate reliable and practical in full-thickness cranial defect reconstructions? J Craniofac Surg 22:12361239,2011

3. Alesch F, Bauer R: Polyacryl prosthesis for cranioplastytheir production in silicon rubber casts. Acta Neurochir (Wien) 77:68-71, 1985

4. Arnedos M, Soria JC, Andre F, Tursz T: Personalized treatments of cancer patients: a reality in daily practice, a costly dream or a shared vision of the future from the oncology community? Cancer Treat Rev 40:1192-1198, 2014

5. Bartus C, William Hanke C, Daro-Kaftan E: A decade of experience with injectable poly-L-lactic acid: a focus on safety. Dermatol Surg 39:698-705, 2013

6. Berman B: 3-D printing: the new industrial revolution. Bus Horiz 55:155-162, 2012

7. Bhaskar IP, Yusheng L, Zheng M, Lee GYF: Autogenous skull flaps stored frozen for more than 6 months: do they remain viable? J Clin Neurosci 18:1690-1693, 2011

8. Bobinski L, Koskinen LO, Lindvall P: Complications following cranioplasty using autologous bone or polymethylmethacrylate-retrospective experience from a single center. Clin Neurol Neurosurg 115:1788-1791, 2013

9. Bodenheimer T: High and rising health care costs. Part 1: seeking an explanation. Ann Intern Med 142:847-854, 2005

10. Caro-Osorio E, De la Garza-Ramos R, Martínez-Sánchez SR, Olazarán-Salinas F: Cranioplasty with polymethylmethacrylate prostheses fabricated by hand using original bone flaps: Technical note and surgical outcomes. Surg Neurol Int 4:136, 2013

11. Cheng CH, Lee HC, Chen CC, Cho DY, Lin HL: Cryopreservation versus subcutaneous preservation of autologous bone flaps for cranioplasty: comparison of the surgical site infection and bone resorption rates. Clin Neurol Neurosurg 124:85-89, 2014

12. D'Urso PS, Earwaker WJ, Barker TM, Redmond MJ, Thompson RG, Effeney DJ, et al: Custom cranioplasty using stereolithography and acrylic. Br J Plast Surg 53:200-204, 2000

13. da Costa DD, Lajarin SF: Comparison of cranioplasty implants produced by machining and by casting in a gypsum mold. Int J Adv Manuf Technol 58:1-8, 2011 
14. Dean D, Min KJ, Bond A: Computer aided design of largeformat prefabricated cranial plates. J Craniofac Surg 14:819-832, 2003

15. El-Katatny I, Masood SH, Morsi YS: Error analysis of FDM fabricated medical replicas. Rapid Prototyping J 16:36-43, 2010

16. Garlotta D: A literature review of poly(lactic acid). J Polym Environ 9:63-84, 2001

17. Goh RCW, Chang CN, Lin CL, Lo LJ: Customised fabricated implants after previous failed cranioplasty. J Plast Reconstr Aesthet Surg 63:1479-1484, 2010

18. Golz T, Graham CR, Busch LC, Wulf J, Winder RJ: Temperature elevation during simulated polymethylmethacrylate (PMMA) cranioplasty in a cadaver model. J Clin Neurosci 17:617-622, 2010

19. Gronet PM, Waskewicz GA, Richardson C: Preformed acrylic cranial implants using fused deposition modeling: a clinical report. J Prosthet Dent 90:429-433, 2003

20. Harris DA, Fong AJ, Buchanan EP, Monson L, Khechoyan D, Lam S: History of synthetic materials in alloplastic cranioplasty. Neurosurg Focus 36(4):E20, 2014

21. Hieu LC, Bohez E, Sloten JV, Phien HN, Vatcharaporn E, Binh PH, et al: Design for medical rapid prototyping of cranioplasty implants. Rapid Prototyping J 9:175-186, 2003

22. Honeybul S, Ho KM: How "successful" is calvarial reconstruction using frozen autologous bone? Plast Reconstr Surg 130:1110-1117, 2012

23. Honeybul S, Ho KM: The current role of decompressive craniectomy in the management of neurological emergencies. Brain Inj 27:979-991, 2013

24. Huang SH, Liu P, Mokasdar A, Hou L: Additive manufacturing and its societal impact: a literature review. Int J Adv Manuf Technol 67:1191-1203, 2012

25. Jaberi J, Gambrell K, Tiwana P, Madden C, Finn R: Longterm clinical outcome analysis of poly-methyl-methacrylate cranioplasty for large skull defects. J Oral Maxillofac Surg 71:e81-e88, 2013

26. Jamshidian M, Tehrany EA, Imran M, Jacquot M, Desobry S: Poly-lactic acid: production, applications, nanocomposites, and release studies. Compr Rev Food Sci F 9:552-571, 2010

27. Kim BJ, Hong KS, Park KJ, Park DH, Chung YG, Kang SH: Customized cranioplasty implants using three-dimensional printers and polymethyl-methacrylate casting. J Korean Neurosurg Soc 52:541-546, 2012

28. Kung WM, Chen ST, Lin CH, Lu YM, Chen TH, Lin MS: Verifying three-dimensional skull model reconstruction using cranial index of symmetry. PLoS One 8:e74267, 2013

29. Kung WM, Lin MS: A simplified technique for polymethyl methacrylate cranioplasty: combined cotton stacking and finger fracture method. Brain Inj 26:1737-1742, 2012

30. Lasprilla AJR, Martinez GAR, Lunelli BH, Jardini AL, Filho RM: Poly-lactic acid synthesis for application in biomedical devices - a review. Biotechnol Adv 30:321-328, 2012

31. Lee SC, Wu CT, Lee ST, Chen PJ: Cranioplasty using polymethyl methacrylate prostheses. J Clin Neurosci 16:56-63, 2009

32. Lemée JM, Petit D, Splingard M, Menei P: Autologous bone flap versus hydroxyapatite prosthesis in first intention in secondary cranioplasty after decompressive craniectomy: a French medico-economical study. Neurochirurgie 59:6063,2013

33. Lethaus B, Bloebaum M, Koper D, Poort-Ter Laak M, Kessler P: Interval cranioplasty with patient-specific implants and autogenous bone grafts - success and cost analysis. J Craniomaxillofac Surg 42:1948-1951, 2014

34. Lin AY, Kinsella CR Jr, Rottgers SA, Smith DM, Grunwaldt LJ, Cooper GM, et al: Custom porous polyethylene implants for large-scale pediatric skull reconstruction: early outcomes. J Craniofac Surg 23:67-70, 2012
35. Magnan B, Bondi M, Maluta T, Samaila E, Schirru L, Dall'Oca C: Acrylic bone cement: current concept review. Musculoskelet Surg 97:93-100, 2013

36. Maravelakis E, David K, Antoniadis A, Manios A, Bilalis N, Papaharilaou Y: Reverse engineering techniques for cranioplasty: a case study. J Med Eng Technol 32:115-121, 2008

37. Munro IR, Guyuron B: Split-rib cranioplasty. Ann Plast Surg 7:341-346, 1981

38. O'Reilly EB, Barnett S, Madden C, Welch B, Mickey B, Rozen S: Computed-tomography modeled polyether ether ketone (PEEK) implants in revision cranioplasty. J Plast Reconstr Aesthet Surg 68:329-338, 2015

39. Peniston SJ, Choi SJ: Effect of sterilization on the physicochemical properties of molded poly(L-lactic acid). J Biomed Mater Res B Appl Biomater 80:67-77, 2007

40. Rengier F, Mehndiratta A, von Tengg-Kobligk H, Zechmann $\mathrm{CM}$, Unterhinninghofen R, Kauczor HU, et al: 3D printing based on imaging data: review of medical applications. Int $\mathbf{J}$ CARS 5:335-341, 2010

41. Rosenthal G, Ng I, Moscovici S, Lee KK, Lay T, Martin C, et al: Polyetheretherketone implants for the repair of large cranial defects: a 3-center experience. Neurosurgery 75:523529,2014

42. Sanan A, Haines SJ: Repairing holes in the head: a history of cranioplasty. Neurosurgery 40:588-603, 1997

43. Shah AM, Jung H, Skirboll S: Materials used in cranioplasty: a history and analysis. Neurosurg Focus 36(4):E19, 2014

44. Singla N, Parkinson Singh S, Gupta SK, Karthigeyan M, Radotra BD: Histopathology of subcutaneously preserved autologous bone flap after decompressive craniectomy: a prospective study. Acta Neurochir (Wien) 156:1369-1373, 2014

45. Smith EJ, Anstey JA, Venne G, Ellis RE: Using additive manufacturing in accuracy evaluation of reconstructions from computed tomography. Proc Inst Mech Eng H 227:551-559, 2013

46. Sorour M, Caton WL III, Couldwell WT: Technique for methyl methacrylate cranioplasty to optimize cosmetic outcome. Acta Neurochir (Wien) 156:207-209, 2014

47. Staffa G, Nataloni A, Compagnone C, Servadei F: Custom made cranioplasty prostheses in porous hydroxy-apatite using 3D design techniques: 7 years experience in 25 patients. Acta Neurochir (Wien) 149:161-170, 2007

48. Stoodley MA, Abbott JR, Simpson DA: Titanium cranioplasty using 3-D computer modelling of skull defects. J Clin Neurosci 3:149-155, 1996

49. Turgut G, Özkaya Ö, Kayali MU: Computer-aided design and manufacture and rapid prototyped polymethylmethacrylate reconstruction. J Craniofac Surg 23:770-773, 2012

50. van Gool AV: Preformed polymethylmethacrylate cranioplasties: report of 45 cases. J Maxillofac Surg 13:2-8, 1985

51. Viterbo F, Palhares A, Modenese E: Cranioplasty: the autograft option. J Craniofac Surg 6:80-83, 1995

52. Vleggaar D, Fitzgerald R, Lorenc ZP: Composition and mechanism of action of poly-L-lactic acid in soft tissue augmentation. J Drugs Dermatol 13 (4 Suppl):s29-s31, 2014

53. Werndle MC, Crocker M, Zoumprouli A, Papadopoulos MC: Modified acrylic cranioplasty for large cranial defects. Clin Neurol Neurosurg 114:962-964, 2012

54. Winder J, Cooke RS, Gray J, Fannin T, Fegan T: Medical rapid prototyping and $3 \mathrm{D} \mathrm{CT}$ in the manufacture of custom made cranial titanium plates. J Med Eng Technol 23:26-28, 1999

55. World Health Organization: WHO Global Health Expenditure Atlas. Geneva: World Health Organization, 2014, pp 2-6

56. Wurm G, Tomancok B, Holl K, Trenkler J: Prospective study on cranioplasty with individual carbon fiber reinforced polymer (CFRP) implants produced by means of stereolithography. Surg Neurol 62:510-521, 2004 
57. Yamamoto Y, Mendel E, Raffel C: Acrylic cranioplasty with alginate molding: technical note. Neurosurgery 41:305-309, 1997

58. Zonenshayn M, Kronberg E, Souweidane MM: Cranial index of symmetry: an objective semiautomated measure of plagiocephaly. Technical note. J Neurosurg 100 (5 Suppl Pediatrics):537-540, 2004

\section{Disclosure}

The authors report no conflict of interest concerning the materials or methods used in this study or the findings specified in this paper.

\section{Supplemental Information \\ Previous Presentation}

Portions of this work were presented as an oral paper presentation at the 10th Asian Congress of Neurological Surgeons, Astana, Kazakhstan, September 12, 2014.

\section{Author Contributions}

Conception and design: all authors. Acquisition of data: Tan, Ling. Analysis and interpretation of data: all authors. Drafting the article: Tan. Critically revising the article: all authors. Reviewed submitted version of manuscript: all authors. Approved the final version of the manuscript on behalf of all authors: Tan. Administrative/technical/material support: Tan. Study supervision: Dinesh.

\section{Correspondence}

Eddie T. W. Tan, Department of Neurosurgery, National Neuroscience Institute, 11 Jalan Tan Tock Seng, Singapore 308433, Singapore. email: eddie_tan@nni.com.sg. 